\title{
Humidifier Development and Applicability to the Next Generation Portable Life Support System
}

\author{
Bruce Conger $^{1}$ \\ Hamilton Sundstrand, Houston, Texas 77058 \\ Robert Sompayrac ${ }^{2}$ \\ Hamilton Sundstrand, Houston, Texas 77058 \\ Bruce Barnes ${ }^{3}$ \\ Jacobs Engineering, Houston, Texas 77058 \\ and \\ Heather L. Paul ${ }^{4}$ \\ NASA Johnson Space Center, Houston, Texas 77058
}

\begin{abstract}
A development effort at the NASA Johnson Space Center investigated technologies to determine whether a humidifier would be required in the Portable Life Support System (PLSS) envisioned for future exploration missions. The humidifier has been included in the baseline PLSS schematic since performance testing of the Rapid Cycle Amine (RCA) indicates that the RCA over-dries the ventilation gas stream. Performance tests of a developmental humidifier unit and commercial off-the-shelf (COTS) units were conducted in December 2009. Following these tests, NASA revisited the need for a humidifier via system analysis. Results of this investigation indicate that it is feasible to meet humidity requirements without the humidifier if other changes are made to the PLSS ventilation loop and the Liquid Cooling and Ventilation Garment (LCVG).
\end{abstract}

\footnotetext{
${ }^{1}$ Thermal Lead, Thermal and Environmental Analysis, 2224 Bay Area Blvd., Houston, Texas 77058/JE-5EA.

${ }^{2}$ Thermal Engineer, Thermal and Environmental Analysis, 2224 Bay Area Blvd., Houston, Texas 77058/JE-5EA.

${ }^{3}$ Thermal Engineer, Thermal and Environmental Analysis, 2224 Bay Area Blvd., Houston, Texas 77058/JE-5EA.

${ }^{4}$ Ventilation Lead, Space Suit and Crew Survival Systems Branch, 2102 NASA Parkway, Houston, Texas/EC5.
} 